\title{
Pentingnya Vitamin A Untuk Ibu Menyusui serta Pembuatan Sosis Wortel di Desa Suka Maju Kabupaten Muaro Jambi
}

\author{
Herinawati ${ }^{1}$, Lia Artika Sari ${ }^{2}$, Atika $^{3}$, Iksaruddin ${ }^{4}$ \\ 1,2,3, Jurusan Kebidanan, Poltekkes Kemenkes Jambi \\ ${ }^{4}$ Jurusan Promosi Kesehatan, Poltekkes Kemenkes Jambi \\ Email: herinawati_burhanuddin@yahoo.com
}

Submitted : 08/06/2021

Accepted: 12/06/2021

Published: 28/06/2021

\begin{abstract}
19 million pregnant women are thought to have vitamin A deficiency. Vitamin A deficiency during pregnancy and postpartum can seriously affect the health of the mother and baby. Vitamin $A$ supplementation is sometimes recommended. Although the health consequences of Vitamin A deficiency (VAC) are not well defined, recent data suggest that VAD in women of reproductive age can increase the risk of morbidity and mortality during pregnancy and the early postpartum period. Severe VAC in the mother also poses a loss for newborns because it can result in an increase in mortality in the first month of life. The results showed that Vitamin A deficiency (VAC) is also associated with high morbidity and mortality rates, especially among toddlers. Every year it is estimated that more than 60,000 Indonesian children suffer from severe visual impairment and one third of them become blind which cannot be cured. This is because the consumption of vegetables is still low, including carrots. This community service activity aims to increase the knowledge, attitudes and behavior of the community about the importance of Vitamin A for postpartum and breastfeeding mothers as well as making carrot sausage in Suka Maju Village, RT.09 Mestong District, Muaro Jambi Regency. The target of this service is breastfeeding mothers and posyandu volunteers. This activity is carried out from February to May. Participants who took part in the activities of postpartum mothers and posyandu volunteers, located at the Village Midwife's House RT 09, Mestong District, Muaro Jambi Regency. It is recommended to the puskesmas, village heads to be able to socialize and apply in promoting the processing of foods containing vitamin A in their daily diet.
\end{abstract}

Keywords : carrot, postpartum, vitamin a

Abstrak

19 juta wanita hamil diduga terkena kekurangan vitamin A. Kekurangan vitamin A selama masa kehamilan dan pascapersalinan dapat sangat mempengaruhi kesehatan ibu dan bayi, Suplemen vitamin A terkadang disarankan. Meskipun konsekuensi kesehatan dari kekurangan Vitamin A (KVA) tidak digambarkan dengan baik, data terakhir menunjukkan bahwa KVA pada wanita usia reproduksi dapat meningkatkan resiko kesakitan dan kematian selama kehamilan dan periode awal post partum. KVA yang berat pada maternal juga memberikan kerugian bagi anak baru lahir karena dapat akibatkan peningkatan kematian dibulan pertama kehidupan. Hasil penelitian menunjukkan bahwa kekurangan Vitamin A (KVA) ini berkaitan pula dengan tingginya angka kesakitan dan angka kematian, khususnya dikalangan balita. Setiap tahunnya diperkirakan lebih dari 60.000 anak Indonesia menderita gangguan penglihatan tingkat berat dan sepertiga dari mereka menjadi buta yang tidak mungkin disembuhkan. Hal ini disebabkan karena konsumsi sayuran yang masih rendah diantaranya wortel. Kegiatan Pengabdian masyarakat ini bertujuan untuk untuk Meningkatkan pengetahuan, sikap dan perilaku masyarakat pentingnya Vitamin A untuk ibu nifas dan ibu menyusui serta pembuatan sosis wortel didesa Suka Maju RT.09 Kecamatan Mestong Kabupaten Muaro Jambi. Sasaran pengabdian ini ibu menyusui dan kader posyandu. Kegiatan ini dilaksanakan dari bulan Februari sampai Mei. Peserta yang mengikuti kegiatan ibu nifas dan kader posyandu, Bertempat di Rumah Bidan Desa RT 09 Kecamatan Mestong Kabupaten Muaro Jambi. Disarankan kepada kepada pihak puskesmas, kepala desa agar dapat mensosialisasikan dan mengaplikasikan dalam menggalakkan pengolahan makanan yang mengandung vitamin A dalam makanan seharihari.

Kata Kunci : ibu nifas, vitamin a, wortel 


\section{PENDAHULUAN}

Kekurangan vitamin A (KVA) tetap merupakan masalah kesehatan masyarakat yang signifikan di seluruh dunia, terutama di sebagian wilayah Afrika dan Asia Tenggara. 19 juta wanita hamil diduga terkena kekurangan vitamin A. Kekurangan vitamin A selama masa kehamilan dan pascapersalinan dapat sangat mempengaruhi kesehatan ibu dan bayi, Suplemen vitamin A terkadang disarankan.

Vitamin A merupakan salah satu zat gizi penting yang larut dalam lemak dan disimpan dalam hati, tidak dapat dibuat oleh tubuh, sehingga harus dipenuhi dari luar (esensial), berfungsi untuk penglihatan, pertumbuhan dan meningkatkan daya tahan tubuh terhadap penyakit.

Meskipun konsekuensi kesehatan dari kekurangan Vitamin A (KVA) tidak digambarkan dengan baik, data terakhir menunjukkan bahwa KVA pada wanita usia reproduksi dapat meningkatkan resiko kesakitan dan kematian selama kehamilan dan periode awal post partum. KVA yang berat pada maternal juga memberikan kerugian bagi anak baru lahir karena dapat akibatkan peningkatan kematian dibulan pertama kehidupan.

Hasil penelitian Checkley et al di New England Journal of Medicine(2010), menunjukkan bahwa, di daerah endemik dengan defisiensi vitamin A (retinol), anakanak yang ibunya menerima suplementasi vitamin A sebelum, selama, dan selama 6 bulan setelah kehamilan memiliki fungsi paru-paru yang lebih baik ketika mereka diuji pada 9 sampai 11 tahun daripada anakanak yang ibunya menerima suplemen beta karoten atau plasebo. Selain itu, mereka menemukan bahwa periode di mana suplementasi dengan vitamin A yang paling penting adalah dari kehamilan usia post natal dari 6 bulan.

Sejumlah penelitian juga memperlihatkan bahwa ASI dari ibu dengan status vitamin A yang buruk sering kali turut menyebabkan peningkatan kerentanan pada bayi. Hasil kajian berbagai studi menyatakan bahwa vitamin A merupakan zat gizi yang esensial bagi manusia, karena zat gizi ini sangat penting dan konsumsi makanan kita cenderung belum mencukupi dan masih rendah sehingga harus dipenuhi dari luar.

Ibu yang sedang dalam masa nifas yang cukup mendapat vitamin A akan meningkatkan kandungan vitamin A dalam air susu ibu (ASI), sehingga bayi yang disusui lebih kebal terhadap penyakit. Di samping itu kesehatan ibu lebih cepat pulih. Upaya perbaikan status vitamin A harus mulai sedini mungkin pada masa kanak-kanak terutama anak yang menderita KVA.

Hasil penelitian juga menunjukkan bahwa kekurangan zat gizi ini berkaitan pula dengan tingginya angka kesakitan dan angka kematian, khususnya dikalangan balita. Setiap tahunnya diperkirakan lebih dari 60.000 anak Indonesia menderita gangguan penglihatan tingkat berat dan sepertiga dari mereka menjadi buta yang tidak mungkin disembuhkan. Hal ini disebabkan karena konsumsi sayuran yang masih rendah diantaranya wortel.

Wortel (Daucus carota L) merupakan sayuran yang multi khasiat bagi pelayanan kesehatan masyarakat luas. Diindonesia konsumsi wortel sangat dianjurkan sebagai bahan pangan potensial untuk mengentaskan masalah penyakit kekurangan vitamin A. Wortel merupakan bahan pangan (sayuran) yang digemari dan dapat dijangkau oleh seluruh lapisan masyarakat.

Wortel mempunyai kandungan gizi yang diperlukan tubuh terutama sebagai sumber pro-vitamin A atau beta karoten. Kandungan pro-vitamin A yang terdapat pada wortel adalah $12.000 \mathrm{SI}$ atau $7125 \mu \mathrm{g}$ ( $1 \mathrm{SI}=0,6 \mu \mathrm{g}$ beta karoten). Pro-vitamin A merupakan senyawa kimia pembentuk 
vitamin A yang sangat diperlukan untuk penglihatan, pertumbuhan dan perkembangan serta mempertahankan jaringan epitel dalam keadaan sehat. Wortel merupakan bahan pangan (sayuran) yang digemari dan dapat dijangkau oleh seluruh lapisan masyarakat. Bahkan mengkonsumsi wortel sangat dianjurkan, terutama untuk menghadapi masalah kekurangan vitamin A. Dalam setiap 100 gram bahan mengandung 12.000 S.I vitamin A, serta kaya akan $\beta$-karoten, merupakan bahan pangan bergizi tinggi, harga murah dan mudah di dapat.

Penambahan wortel pada makanan diharapkan dapat meningkatkan nilai gizi makanan terutama dapat meningkatkan kandungan $\beta$ karoten pada makanan dan dengan penambahan wortel pada makanan juga dapat menambah variasi makanan.

Namun selama ini wortel belum dimanfaatkan secara optimal, karena hanya dimanfaatkan dalam pengolahan sayur seperti sup, tumis, dan capcay dan juga sebagian besar masyarakat tidak menyukai mengkonsumsi wortel. Oleh karena itu dalam upaya peningkatan konsumsi wortel pada masyarakat alternatifnya adalah dengan mengolahnya menjadi bahan tambahan untuk pembuatan sosis.

Politeknik Kesehatan (Poltekkes) Jambi sebagai institusi pendidikan tinggi yang mempunyai tugas melaksanakan Tri Darma Perguruan tinggi : Pendidikan pengajaran, penelitian, dan pengabdian masyarakat berusaha merealisasikan kegiatan pengabdian masyarakat sebagai sarana atau tempat untuk mempraktekan teori yang didapat di kampus secara langsung dan nyata di masyarakat, sehingga Poltekkes dapat berkontribusi membantu masyarakat dalam menumbuhkan, membina, dan mengembangkan partisipasi masyarakat di bidang pembangunan kesehatan terutama kesehatan ibu dan anak sehingga masyarakat sadar akan kesehatannya dan dapat mengatasi masalah kesehatannya sendiri.

\section{TARGET DAN LUARAN}

1. Target

Kontribusi mendasar dari kegiatan ini adalah peningkatan kemampuan masyarakat dalam merencanakan, melaksanakan dan mengevaluasi upaya promosi kesehatan dan pencegahan penyakit yang dilakukan secara mandiri dan sesuai dengan kebutuhan kesehatan masyarakat di Desa Suka Maju Kecamatan Mestong Kota Kabupaten Muaro Jambi.

2. Luaran

Target luaran dari kegiatan ini adalah dilaksanakannya Gerakan Masyarakat Hidup Sehat (GERMAS) melalui pengolahan makanan di Desa Suka Maju Kecamatan Mestong Kabupaten Muaro Jambi.

\section{METODE PELAKSANAAN}

Kegiatan dihadiri oleh ibu menyusui dan ibu Kader posyandu serta Bidan Desa Suka Maju. Kegiatan yang dilakukan yaitu penyuluhan tentang pentingnya vitamin A untuk ibu nifas dan menyusui kemudian kegiatan pembuatan sosis wortel di lanjutkan kegiatan tanya jawab serta diskusi dan yang terakhir melakukan evaluasi materi dan pembutan sosis wortel

\section{HASIL DAN PEMBAHASAN}

Pelaksanaan kegiatan pengabdian masyarakat dilaksanakan di rumah bidan desa suka maju kecamatan Mestong Kabupaten Muaro Jambi. Kegiatan ini dilaksanakan pada bulan Februari - Juni. Hasil dari beberapa tahapan pelaksanaan pada kegiatan pengabdian masyarakat yaitu tahap perencanaan sudah dilakukan pertemuan dan kerjasama dengan pihak Pak Lurah, Kepala Pustu, Bidan, Kader serta Kepala Desa untuk pelaksanaan penyuluhan pemberian penyuluhan pentingnya vitamin A untuk ibu nifas dan ibu menyusui serta pembuatan sosis wortel di Desa Suka Maju.

Tahap pelaksanaan dilakukan dengan penyuluhan pentingnya vitamin A untuk ibu nifas dan menyusui menggunakan buku saku. Pada ibu hamil dan menyusui, vitamin A 
berperan penting untuk memelihara kesehatan ibu selama masa kehamilan dan menyusui. Buta senja pada ibu menyusui, suatu kondisi yang kerap terjadi karena kurang vitamin A (KVA).

Berdasarkan penelitian yang dilakukan oleh Deni Mryani (2019) menyimpulkan bahwa konsumsi vitamin A pada ibu postpartum dan nifas bertujuan untuk pencegahan dini terhadap kekurangan vitamin A agar bayi terlindungi dari Xeroftalmia. Kegiatan selanjutnya yaitu demonstrasi pembuatan sosis wortel. Sebuah wortel ukuran sedang mengandung sekitar 12.000 SI beta-karoten. Kandungan betakaroten pada wortel dapat mencegah terjadinya penyakit kanker, yaitu dengan jalan mengacaukan mekanisme kanker yang merusak sel. Selain itu beta-karoten wortel juga dapat mencegah penyakit rabun senja, diare, serta memegang peranan penting dalam kesuburan. Adapun dokumentasi kegiatan dapat dilihat pada gambar berikut:

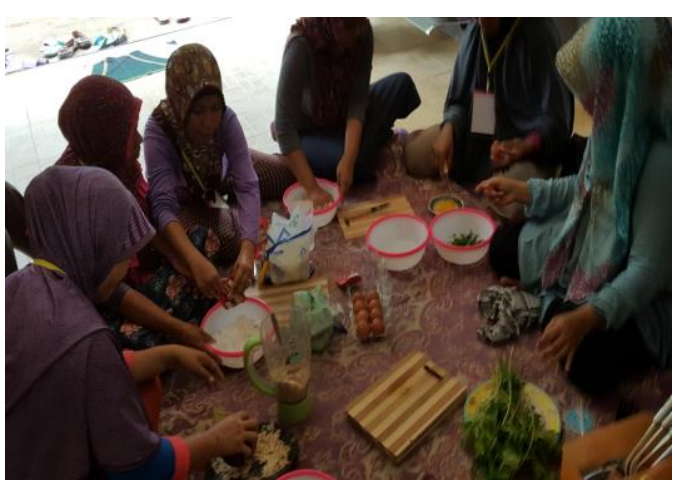

Gambar 1.Penjelasan dan praktik pembuatan sosis wortel

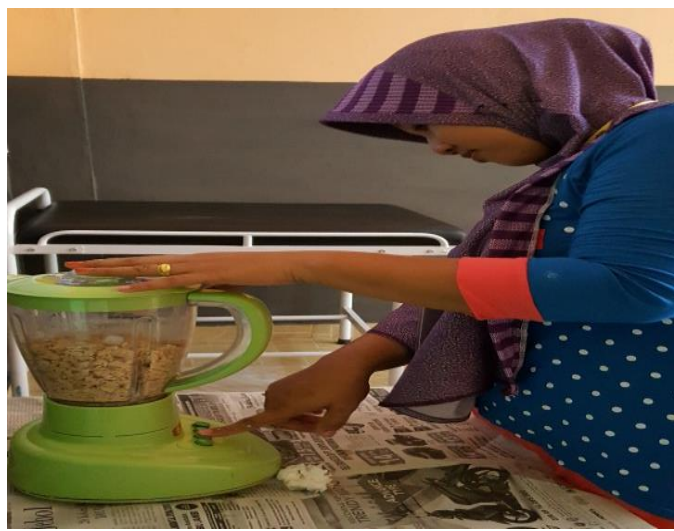

Gambar 2.

Proses pembuatan sosis wortel

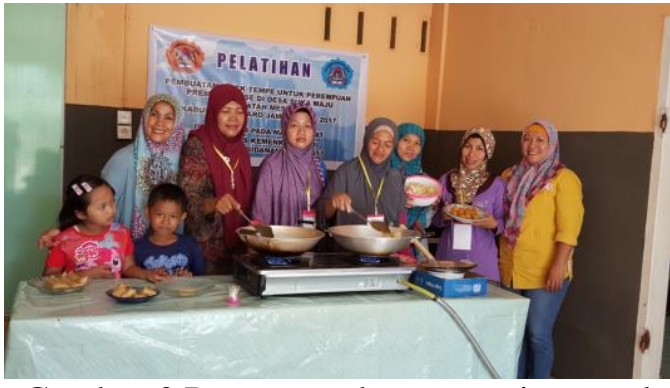

Gambar 3.Proses pembuatan sosis wortel

Tahap evaluasi yaitu mengevaluasi pemahaman pengetahuan mengenai materi yang telah dijelaskan dan pembuatan sosis wortel melalui diskusi dan tanya jawab.

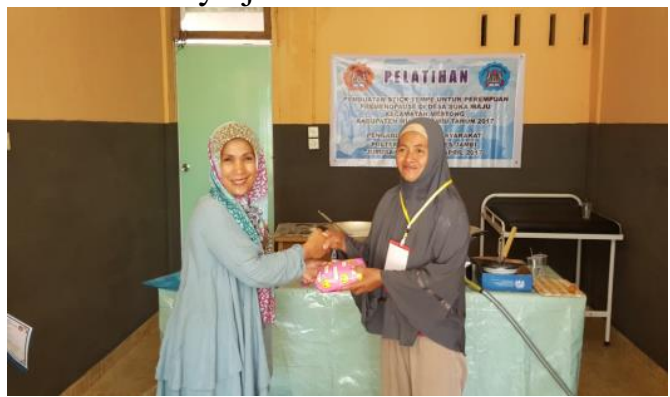

Gambar 4.Pemberian hadiah kepada peserta

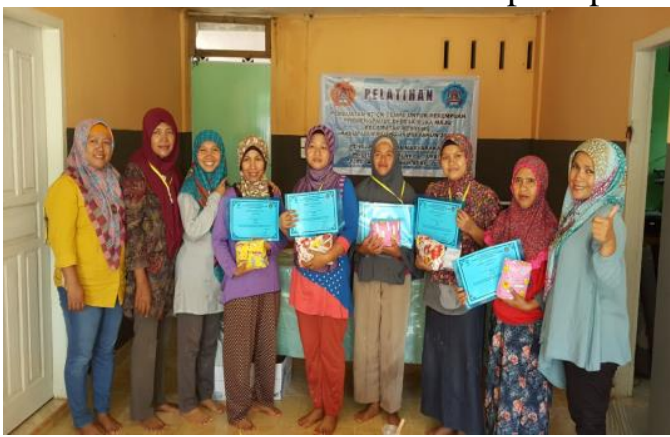

Gambar 5. Pemberian sertifikat dan cendera mata kepada peserta

\section{KESIMPULAN DAN SARAN}

1. Kesimpulan

Kegiatan pengabdian masyarakat ini dapat disimpulkan bahwa tingkat ketercapaian target sudah tercapai dengan baik, ketepatan masalah dengan metode yang diterapkan sudah cukup dan terjadi peningkatan pengetahuan dan keterampilan ibu menyusui dan kader posyandu dalam pembuatan sosis berbahan dasar wortel di Desa Suka Maju.

2. Saran

Disarankan kepada kepada pihak puskesmas, kepala desa agar dapat 
mensosialisasikan dan mengaplikasikan dalam menggalakkan pengolahan makanan yang mengandung vitamin A dalam makanan sehari-hari.

\section{UCAPAN TERIMAKASIH}

Terima kasih tim ucapkan kepada seluruh pihak yang telah membantu kegiatan ini terlaksana terutama direktur Poltekkes Kemenkes Jambi, pihak pemerintah setempat dan para tim

\section{DAFTAR PUSTAKA}

Almatsier, Sunit., 2011. Prinsip Dasar Ilmu Gizi. Gramedia Pustaka Utama. Jakarta.

Astawan, M. 2011 Sehat dengan Hidangan Hewani, Penebar Swadaya Jakarta

Berlian Nur, dan Hartuti, 2013. Wortel dan Lobak. Penebar Swadaya. Jakarta

Harwono, P. A 2011. Beta Karoten Vitamin Untuk Kesehatan Mata. Dari http://id.wikipedia.org/wiki/beta-karotenvitamin-untuk-mata. (Diakses tangga 19 juni 2012)

Ketty Husnia Wardany, 2018 Seri Apotek Dapur: Raja Obat Alami Wortel Si Orange Kaya Nutrisi, Andi Publisher

Sumoprastowo, R M. 2000. Memilih dan Menyimpan Sayur-Mayur, Buah-Buahan, dan Bahan Makanan. PT Bumi Aksara, Jakarta

Vitamin A supplementation in Brazilian pregnant and postpartum women: a systematic review. Paulo Augusto Ribeiro Neves, Cláudia Saunders, Denise Cavalcante de Barros, Andréa Ramalho Original Article

Oliveira-Menegozzo JM, Bergamaschi DP, Middleton P, East CE. Vitamin A supplementation for postpartum women (Review). Cochrane Database of Systematic Reviews 2010, Issue 10. Art. No.: CD005944. DOI: 10.1002/14651858.CD005944.pub2

William Checkley, M.D., Ph.D., Keith P. West, Jr., Dr.P.H., Robert A. Wise, M.D., Matthew R. Baldwin, M.D., Lee Wu, M.H.S., Steven C. LeClerq, M.H.S., Parul Christian, Dr.P.H., Joanne Katz, Sc.D., James M. Tielsch, Ph.D., Subarna Khatry, M.D., and Alfred Sommer, M.D., M.H.S, 2010 Maternal Vitamin A Supplementation and Lung Function in Offspring, The New England and Journal Of Medicine.

WHO Guideline: Vitamin A Supplementation in Postpartum Women. Geneva: WHO, 2011 